\title{
Trends in the Epidemiology of Osteomyelitis
}

\author{
A Population-Based Study, 1969 to 2009
}

\author{
Hilal Maradit Kremers, MD, MSc, Macaulay E. Nwojo, MD, Jeanine E. Ransom, BS, \\ Christina M. Wood-Wentz, MS, L. Joseph Melton III, MD, and Paul M. Huddleston III, MD \\ Investigation performed at the Departments of Health Sciences Research and Orthopedic Surgery, Mayo Clinic, Rochester, Minnesota
}

\begin{abstract}
Background: The epidemiology of osteomyelitis in the United States is largely unknown. The purpose of this study was to determine long-term secular trends in the incidence of osteomyelitis in a population-based setting.

Methods: The study population comprised 760 incident cases of osteomyelitis first diagnosed between January 1 , 1969, and December 31, 2009, among residents of Olmsted County, Minnesota. The complete medical records for each potential subject were reviewed to confirm the osteomyelitis diagnosis and to extract details on anatomical sites, infecting organisms, etiological risk factors, and outcomes.
\end{abstract}

Results: The overall age and sex-adjusted annual incidence of osteomyelitis was 21.8 cases per 100,000 person-years. The annual incidence was higher for men than for women and increased with age $(p<0.001)$. Rates increased with the calendar year $(p<0.001)$ from 11.4 cases per 100,000 person-years in the period from 1969 to 1979 to 24.4 per 100,000 person-years in the period from 2000 to 2009 . The incidence remained relatively stable among children and young adults but almost tripled among individuals older than sixty years; this was partly driven by a significant increase in diabetes-related osteomyelitis from 2.3 cases per 100,000 person-years in the period from 1969 to 1979 to 7.6 cases per 100,000 person-years in the period from 2000 to 2009 ( $p<0.001)$. Forty-four percent of cases involved Staphylococcus aureus infections.

Conclusions: The reasons for the increase in osteomyelitis between 1969 and 2009 are unclear but could comprise a variety of factors, including changes in diagnosing patterns or increases in the prevalence of risk factors (e.g., diabetes) in this population.

Level of Evidence: Prognostic Level III. See Instructions for Authors for a complete description of levels of evidence.

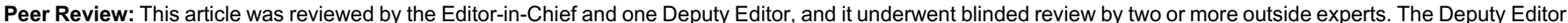

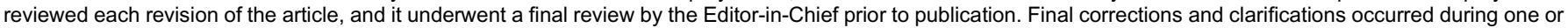
more exchanges between the author(s) and copyeditors.

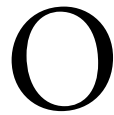
steomyelitis is a heterogeneous disease in its pathophysiology, clinical presentation, and management ${ }^{1}$. Osteomyelitis can be due to contiguous spread of infection from adjacent soft tissues and joints, hematogenous seeding, or direct inoculation of bacteria into the bone as a result of trauma or surgery ${ }^{1,2}$. The diagnosis and treatment of osteomyelitis have improved over the previous decades, and a systematic classification and staging system aids in defining treatment plans ${ }^{3,4}$. Along with advances in bone regeneration, the techniques of debridement and reconstruction of infected osseous defects have changed ${ }^{5-9}$, and the development of new antibiotics and delivery systems has helped to decrease the medical treatment burden and the length of hospitalizations ${ }^{10-13}$. Additionally, vascular and microvascular surgery has improved soft-tissue management and healing, while internal fixation and advances in implant technology and organized multidisciplinary trauma teams have greatly improved the care of trauma patients ${ }^{14}$. Nevertheless, diabetes mellitus-related infections and infections of the axial or appendicular skeleton remain as devastating complications, often requiring complex multidisciplinary care with mixed outcomes.

Disclosure: None of the authors received payments or services, either directly or indirectly (i.e., via his or her institution), from a third party in support of any aspect of this work. None of the authors, or their institution(s), have had any financial relationship, in the thirty-six months prior to submission of this work, with any entity in the biomedical arena that could be perceived to influence or have the potential to influence what is written in this work. Also, no author has had any other relationships, or has engaged in any other activities, that could be perceived to influence or have the potential to influence what is written in this work. The complete Disclosures of Potential Conflicts of Interest submitted by authors are always provided with the online version of the article. 
As advances are made in the management of osteomyelitis, the epidemiology of the condition appears to have evolved over time. The increased survival following traumatic injury has been accompanied by an increased occurrence of posttraumatic osteomyelitis $^{15,16}$. Similarly, improved life expectancy among elderly patients with diabetes mellitus has resulted in more cases of neuropathy, vascular insufficiency, and the associated local complications of soft-tissue loss, bone destruction, and osteomyelitis ${ }^{17,18}$. To date, however, there are only a handful of epidemiological studies of osteomyelitis in the U.S., and these studies are limited to selected subsets of patients, as defined by age $^{19}$, osteomyelitis type ${ }^{20}$, anatomical location ${ }^{21}$, or infecting organisms $\mathrm{s}^{22,23}$. To our knowledge, there are no comprehensive epidemiological studies describing the entire spectrum of osteomyelitis in the U.S. With this background, our objective was to examine trends in the age and sex-specific incidence of osteomyelitis over a forty-one-year period from 1969 to 2009. We also compared trends in underlying etiology, disease characteristics at initial presentation, medical outcomes, and patient survival.

\section{Materials and Methods}

This population-based historical cohort study was carried out in Olmsted 1 County, Minnesota, using resources of the Rochester Epidemiology Project $^{24-27}$. This is a medical records-linkage system containing medical records from all health-care providers. All medical, surgical, and histologic diagnoses from these health-care providers are entered into computerized indices to facilitate case identification. This population-based data resource ensures virtually complete ascertainment and follow-up of all clinically diagnosed cases of osteomyelitis in a geographically defined community, along with the ability to access original medical records for case validation.

\section{Identification of Incident Osteomyelitis Cases}

We identified all potential patients with osteomyelitis by electronically searching the medical diagnostic and surgical procedure indices, the microbiology culture database, and the radiology database. Nursing home residents were included in the study, whereas prisoners residing in the Federal Medical Center were excluded.

\section{Data Collection}

Using a standardized data collection form, the medical records of all electronically identified potential patients were reviewed manually by trained registered nurse abstractors for clinical documentation, positive cultures, and/ or radiographic diagnoses of osteomyelitis. An orthopaedic surgeon with expertise in osteomyelitis reviewed the records of questionable cases to verify the diagnosis and to determine the incidence date, which was defined as the time of the initial clinical diagnosis (rather than the time of the first biopsy). All patients were classified as having definite, probable, or possible osteomyelitis using criteria similar to those previously used for periprosthetic joint infections $^{28}$. Definite osteomyelitis was defined as at least two bone cultures with microbial growth with the same organism, or one positive bone culture combined with the intraoperative findings of purulence, acute inflammation on histologic examination consistent with infection, or a sinus tract communicating to the bone. Probable osteomyelitis was defined as at least one bone culture or surgically obtained pathologic specimen revealing acute inflammation on histologic examination consistent with infection, or a sinus tract communicating to the bone. Possible osteomyelitis was defined as diagnostic evidence of bone infection on imaging studies, but no available pathologic or microbiologic data. Data analyses included all three groups.

Data elements extracted from the medical records were age, sex, date of first clinic visit for diagnosis and/or treatment of osteomyelitis, anatomical location, laterality (right, left, and axial), method of diagnosis (clinical only, needle biopsy, surgical specimen, and culture), date of first tissue diagnosis, identified organisms if any, clinical classification of etiology (captured under seven categories as diabetes mellitus-related, hematogenous, traumatic, urinary tract infection, septic arthritis, contiguous, and iatrogenic), subsequent amputation(s), date and causes of death if applicable, and the date of last clinical contact.

\section{Statistical Methods}

The entire population over the forty-one-year period was considered to be at risk for developing osteomyelitis. Patient demographics were described as the mean and the standard deviation or as the count and the percentage as appropriate. Age and sex-specific and overall age and sex-adjusted incidence rates were calculated for ten-year time periods and overall from 1969 to 2009. Confidence interval (CI) estimates around the incidence estimates were generated from the Poisson distribution. Age and sex-adjusted estimates were calculated by using the 2010 U.S. Census population data. In order to examine whether the characteristics of the patient population changed over time, we similarly examined clinical characteristics in ten-year intervals. The influence of age, sex, time period, etiology, and their possible interactions were assessed using Poisson regression, with the number of cases as the dependent variable and the corresponding population included as an offset. Poisson regression models were generated with the use of generalized additive models, incorporating age and calendar year as smoothed terms, thereby allowing examination of nonlinear trends over time. All crude rates and univariate and multivariable models of incidence were visually assessed. All tables depicting incidence rates were based on the Poisson models. Expected survival was calculated using the Minnesota white population survival estimates as the reference. All significance tests were two-sided, and $\mathrm{p}<0.05$ was considered significant. The analyses were conducted with SAS software (version 9.3; SAS Institute, Cary, North Carolina) and R software (version 2.14.0; R Foundation for Statistical Computing, Vienna, Austria).

\section{Source of Funding}

No external funds were used for the design and conduct of the study; collection, management, analysis, and interpretation of the data; and preparation, review, or approval of the manuscript. This study was, in part, made possible using the resources of the Rochester Epidemiology Project, which is supported by the National Institute on Aging of the National Institutes of Health under Award Number R01AG034676.

\section{Results}

Over the forty-one-year time period from January 1, 1969, through December 31, 2009, we identified 760 unique Olmsted County residents with new-onset osteomyelitis. The majority of the patients (59\%) were classified as having definite osteomyelitis, but $18 \%$ had probable and $23 \%$ had possible osteomyelitis. Their mean age was $52 \pm 25$ years, and $58 \%$ of the unique patients were male (Table I). The mean age at incidence was higher among females than males ( $56 \pm 26$ versus $49 \pm 25$ years; $\mathrm{p}<0.001)$. The mean age at incidence increased significantly across the four decades, from $38 \pm 26$ years in the period from 1969 to 1979 to $57 \pm 23$ years in the period from 2000 to 2009 ( $\mathrm{p}<0.001$ ). Diabetes was the primary contributing factor in $27 \%$ of the patients, followed in equal proportion by hematogenous (19\%) and trauma-related (19\%) infections. The proportion of diabetes-related cases doubled from $13 \%$ in the 1970 s to $29 \%$ in the 2000 s.

The majority of the infections (94\%) involved only one location, and the most common anatomical sites affected were the tarsal and metatarsal bones and the toes (43\%); the long bones of the lower extremities (20\%); and the spine, sternum, 
TABLE I Characteristics of Incident Osteomyelitis Infections in 760 Olmsted County Residents (1969-2009)

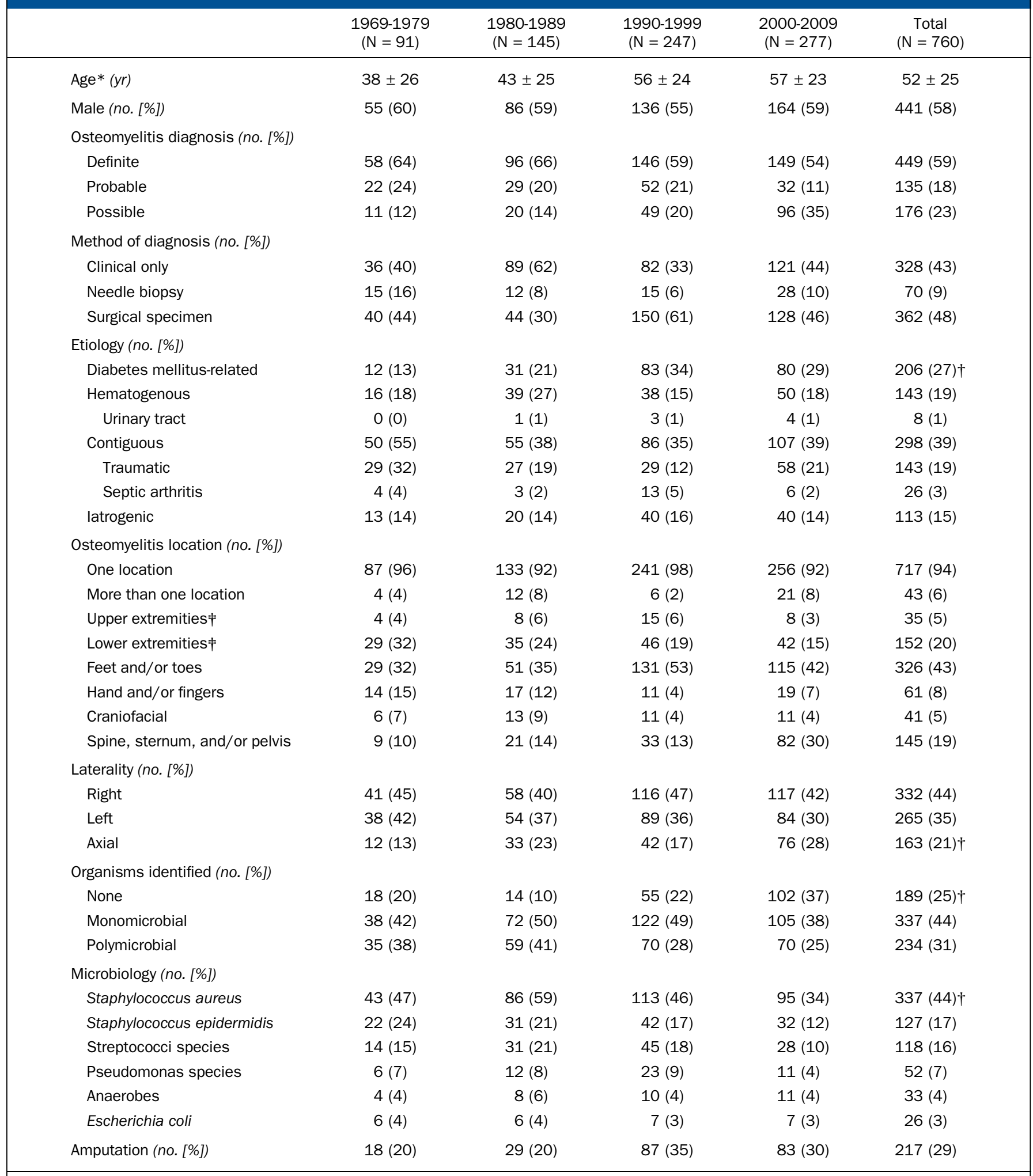

*The values are given as the mean and the standard deviation. $\uparrow \mathrm{P}<0.001$ for trend. $¥$ These numbers refer to long bones of the upper and lower extremities and exclude hand, fingers, feet, and toes. 
The Journal of Bone \& Joint SURGERY $\cdot$ JBJS.org VOlume 97-A $\cdot$ Number $10 \cdot$ May 20, 2015

Trends in The EPidemiology of OSTEOMYelitis

\section{TABLE II Age and Sex-Specific Annual Incidence of Osteomyelitis in Olmsted County (1969-2009)}

\begin{tabular}{|c|c|c|c|c|c|c|}
\hline \multirow[b]{2}{*}{ Age Group (yr) } & \multicolumn{3}{|c|}{ No. of Cases } & \multicolumn{3}{|c|}{ Incidence Rate* (per 100,000 person-years) } \\
\hline & Female & Male & Total & Female & Male & Total \\
\hline$<18$ & 41 & 71 & 112 & 6.6 & 10.9 & 8.8 \\
\hline $18-29$ & 22 & 42 & 64 & 5.0 & 10.9 & 7.8 \\
\hline $30-39$ & 20 & 46 & 66 & 5.7 & 13.2 & 9.4 \\
\hline $40-49$ & 20 & 40 & 60 & 6.8 & 14.0 & 10.4 \\
\hline $60-69$ & 52 & 67 & 119 & 33.4 & 49.2 & 40.8 \\
\hline $70-79$ & 57 & 54 & 111 & 49.4 & 66.7 & 56.5 \\
\hline$\geq 80$ & 61 & 50 & 111 & 70.3 & 128.4 & 88.3 \\
\hline Total & 319 & 441 & 760 & $16.7(14.8,18.6)$ & $27.7(24.9,30.5)$ & $21.8(20.2,23.4)$ \\
\hline
\end{tabular}

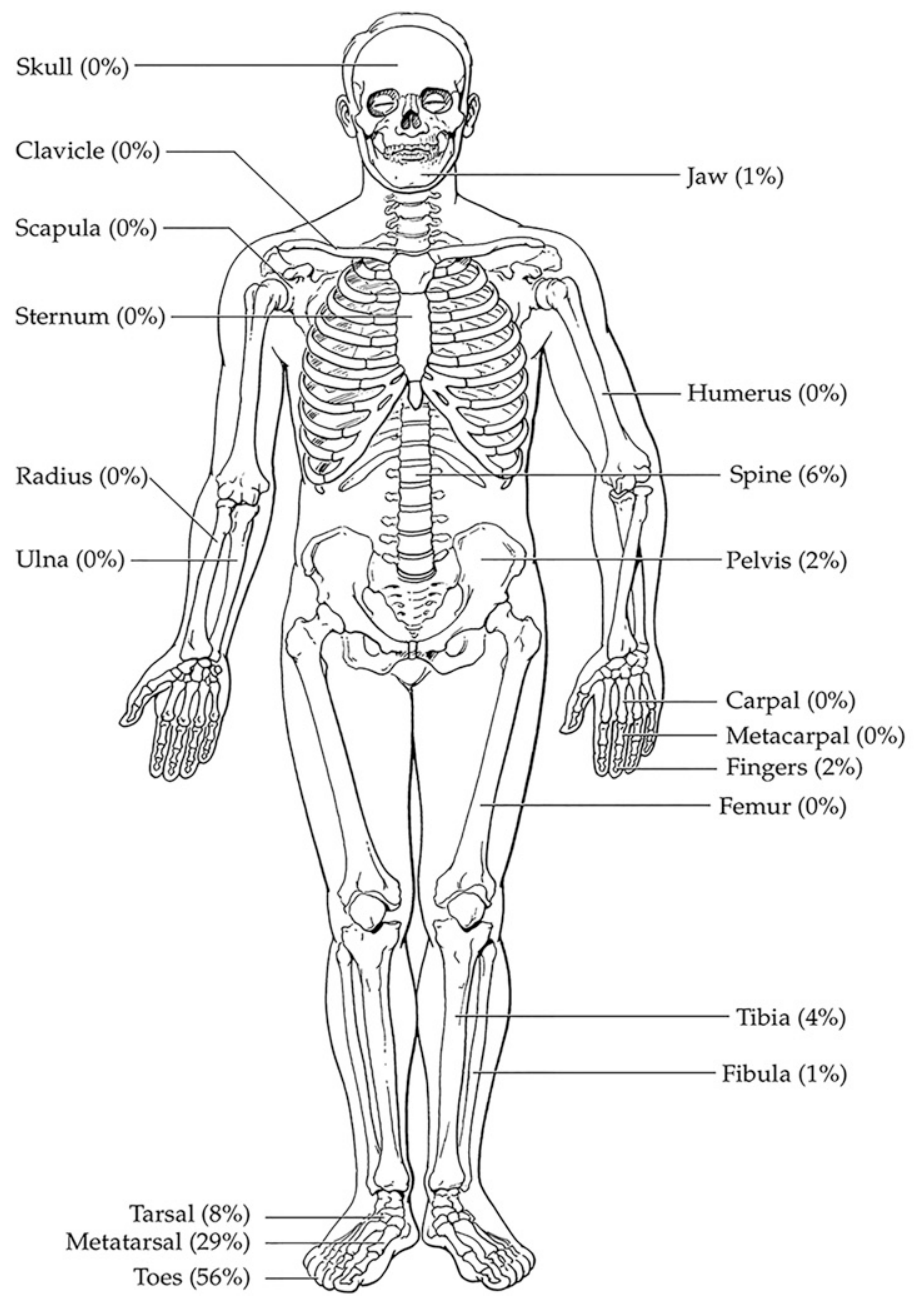

\begin{tabular}{lc}
\hline Mean age, years & $64( \pm 16)$ \\
\hline Male sex (\%) & 55 \\
Laterality (\%) & 56 \\
$\quad$ Right & 36 \\
$\quad$ Left & 8 \\
$\quad$ Axial & 60 \\
Amputation (\%) & 40 \\
Polymicrobial (\%) & $\%$ \\
\hline & 42 \\
\hline Organisms & 22 \\
\hline Staphylococcus aureus & 25 \\
Staphylococcus epidermidis & 8 \\
Streptococci species & 5 \\
Pseudomonas species & 6 \\
Anaerobes & 1 \\
Escherichia coli & 3 \\
Enterobacteriaceae & \\
Proteus species & \\
\hline
\end{tabular}

Fig. 1-A

Figs. 1-A, 1-B, and 1-C Clinical characteristics according to osteomyelitis etiology. (By permission of the Mayo Foundation for Medical Education and Research. All rights reserved.) Fig. 1-A Diabetes mellitus-related osteomyelitis. 
The Journal of Bone \& Joint Surgery JbjS. org Volume 97-A · Number 10 - MaY 20, 2015

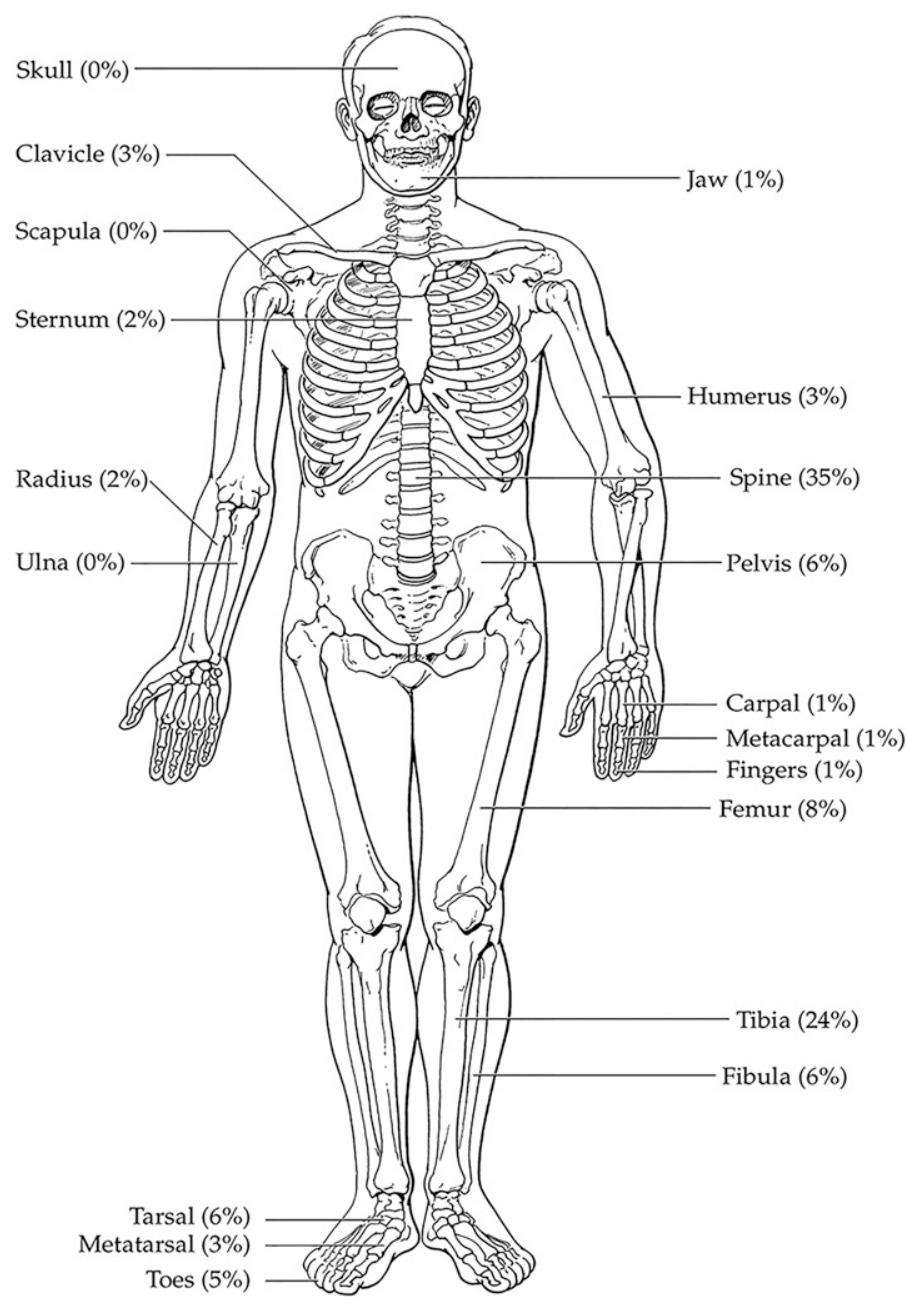

Fig. 1-B

Hematogenous osteomyelitis.

and/or pelvis (19\%). Consistent with temporal trends in the distribution of cases by underlying etiology, there was an increase in patients with osteomyelitis of the feet and/or toes and axial locations, but a decline in lower-extremity osteomyelitis of the long bones. In the latest time period, $42 \%$ of the cases involved the feet and toes, and $28 \%$ involved the axial locations, mostly hematogenous infections of the spine. A small number of patients (6\%) had infections in more than one location. In these patients, each location was identified as a primary location.

Staphylococcus aureus infections were responsible for $44 \%$ of the cases, followed by Staphylococcus epidermidis (17\%) and Streptococcus infections (16\%). We observed a decline in the proportion of patients with Staphylococcus infections and an increase in the proportion of patients with culture-negative cases over time. In a total of 217 patients (29\%), osteomyelitis resulted in amputations at various levels of the extremity.

Clinical characteristics according to osteomyelitis etiology are illustrated in Figures 1-A, 1-B, and 1-C. We observed notable differences in demographics, location, and affecting organisms according to etiology. For example, the mean age was significantly lower in patients with hematogenous osteomyelitis than
TRENDS IN THE EPIDEMIOLOgy of OSTEOMYelitis

\begin{tabular}{lc}
\hline Mean age, years & $\mathbf{3 9 \pm 2 9}$ \\
\hline Male sex (\%) & 60 \\
Laterality (\%) & 29 \\
$\quad$ Right & 29 \\
$\quad$ Left & 42 \\
$\quad$ Axial & 6 \\
Amputation (\%) & 13 \\
Polymicrobial (\%) & $\%$ \\
\hline & 48 \\
\hline Organisms & 7 \\
\hline Staphylococcus aureus & 8 \\
Staphylococcus epidermidis & 3 \\
Streptococci species & 3 \\
Pseudomonas species & 1 \\
Anaerobes & 1 \\
Escherichia coli &
\end{tabular}

in those with diabetes-related osteomyelitis (thirty-nine versus sixty-four years; $\mathrm{p}<0.001$ ). An axial location (mainly the spine) was more common in patients with hematogenous osteomyelitis $(42 \%)$ than in those with diabetes-related (8\%) or contiguous osteomyelitis (16\%). Polymicrobial etiology was uncommon in patients with hematogenous osteomyelitis (13\%) compared with those with diabetes-related osteomyelitis (40\%) and those with contiguous osteomyelitis (35\%). Although S. aureus, S. epidermidis, and Streptococcus species were the most common organisms, S. epidermidis, streptococci species, and anaerobes were less common in hematogenous osteomyelitis. Finally, $60 \%$ of the diabetes-related osteomyelitis cases resulted in amputations compared with $6 \%$ of the hematogenous infections and $24 \%$ of the contiguous infections, mostly involving the toes and the tarsal and metatarsal bones.

\section{Age and Sex-Specific Incidence}

The overall age and sex-adjusted annual incidence of osteomyelitis over the entire forty-one-year time period was 21.8 cases $(95 \% \mathrm{CI}$, 20.2 to 23.4 ) per 100,000 person-years (Table II). The annual incidence was higher in men than in women (27.7 versus 16.7 cases per 100,000 person-years; $p<0.001$ ) and increased with age 
The Journal of Bone \& Joint Surgery $\cdot$ Jbjs.org Volume 97-A - Number $10 \cdot$ May 20, 2015

Trends in the Epidemiology of OSteomyelitis

\section{TABLE III Trends in Age-Specific Incidence of Osteomyelitis in Olmsted County (1969-2009)}

\begin{tabular}{|c|c|c|c|c|c|c|c|c|}
\hline \multirow[b]{2}{*}{ Age Group (yr) } & \multicolumn{8}{|c|}{ Time Period } \\
\hline & No. & Incidence Rate & No. & Incidence Rate & No. & Incidence Rate & No. & Incidence Rate \\
\hline$<18$ & 26 & 7.9 & 28 & 9.9 & 30 & 9.6 & 28 & 8.0 \\
\hline $18-29$ & 15 & 7.3 & 20 & 9.4 & 14 & 7.1 & 15 & 7.2 \\
\hline $30-39$ & 8 & 6.0 & 23 & 13.8 & 19 & 9.4 & 16 & 8.0 \\
\hline $50-59$ & 10 & 12.8 & 17 & 20.6 & 39 & 35.8 & 51 & 31.2 \\
\hline $60-69$ & 11 & 18.9 & 16 & 26.6 & 48 & 65.8 & 44 & 43.8 \\
\hline $70-79$ & 5 & 12.9 & 19 & 45.7 & 45 & 88.4 & 42 & 64.6 \\
\hline$\geq 80$ & 7 & 35.0 & 11 & 43.4 & 39 & 113.5 & 54 & 117.3 \\
\hline Total* & 91 & $11.4(8.8,13.9)$ & 145 & $17.5(14.4,20.6)$ & 247 & $28.6(24.9,32.4)$ & 277 & $24.4(21.5,27.3)$ \\
\hline
\end{tabular}

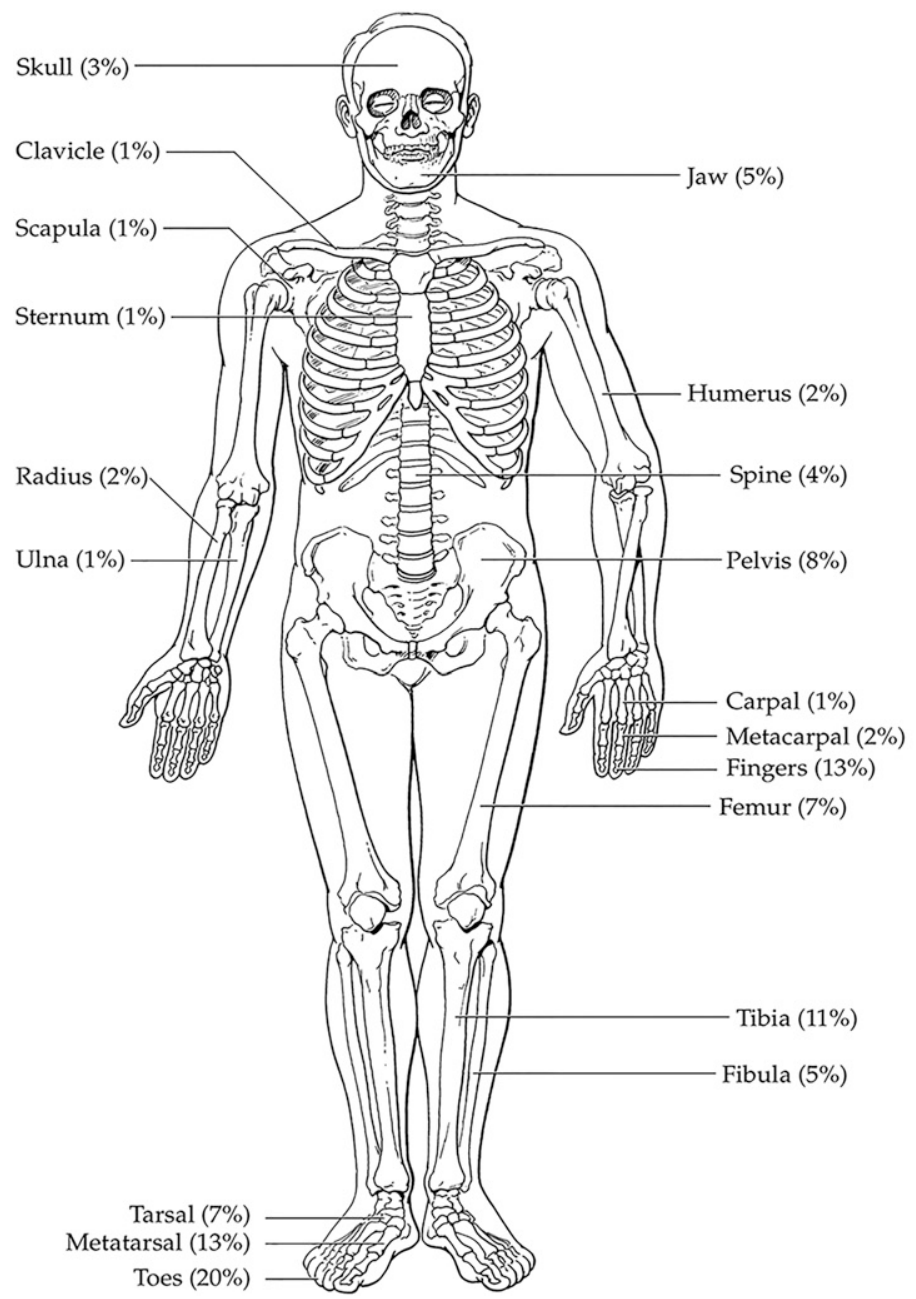

\begin{tabular}{lc}
\hline Mean age, years & $\mathbf{4 9 \pm 2 6}$ \\
\hline Male sex (\%) & 60 \\
Laterality (\%) & \\
$\quad$ Right & 45 \\
$\quad$ Left & 39 \\
$\quad$ Axial & 16 \\
Amputation (\%) & 24 \\
Polymicrobial (\%) & 35 \\
\hline & \\
\hline Organisms & 45 \\
\hline Staphylococcus aureus & 17 \\
Staphylococcus epidermidis & 14 \\
Streptococci species & 3 \\
Pseudomonas species & 3 \\
\hline Enaerobes & 3 \\
\hline
\end{tabular}

Fig. 1-C

Contiguous osteomyelitis. 
TABLE IV Trends in Incidence of Osteomyelitis by Underlying Etiology or Location in Olmsted County (1969-2009)

\begin{tabular}{|c|c|c|c|c|c|c|c|c|}
\hline \multirow[b]{2}{*}{ Etiology or Location } & \multicolumn{8}{|c|}{ Time Period } \\
\hline & No. & Incidence Rate* & No. & Incidence Rate* & No. & Incidence Rate* & No. & Incidence Rate* \\
\hline Diabetes mellitus-related & 12 & $2.3(1.0,3.6)$ & 31 & $4.4(2.8,6.0)$ & 83 & $10.5(8.2,12.9)$ & 80 & $7.6(5.9,9.2)$ \\
\hline Hematogenous & 16 & $1.4(0.7,2.2)$ & 39 & $4.4(2.9,5.9)$ & 38 & $3.6(2.4,4.8)$ & 50 & $4.2(3.0,5.4)$ \\
\hline
\end{tabular}

*Age and sex-adjusted incidence rates per 100,000 person-years; values in parentheses are the 95\% $\mathrm{Cl}$.

$(\mathrm{p}<0.001)$. The male preponderance was evident in all age groups. The annual incidence of osteomyelitis was less than eleven cases per 100,000 person-years until the sixth decade of life. Thereafter, incidence rates increased steeply with age, corresponding to a roughly $50 \%$ increase in incidence per decade of life. The highest incidence was among elderly men (128 cases per 100,000 personyears for those at least eighty years old).

\section{Time Trends in Incidence}

Incidence rates increased significantly $(\mathrm{p}<0.001)$ over time (Table III). The overall age and sex-adjusted incidence was 11.4 cases per 100,000 person-years in the period from 1969 to 1979 and increased to 24.4 cases per 100,000 person-years in the period from 2000 to 2009. These trends were similar for both males and females. Consistent with trends by etiology, incidence rates remained relatively stable among children and young adults (less than fifty years old) but almost tripled among individuals at least sixty years of age.

We observed an increase in incidence in all categories of osteomyelitis over time but most notably in diabetes-related cases and vertebral osteomyelitis (Table IV). The age and sex-adjusted incidence of diabetes-related osteomyelitis increased significantly from 2.3 cases per 100,000 person-years in the period from 1969 to 1979 to 10.5 cases per 100,000 person-years in the period from 1990 to 1999 and then declined to 7.6 cases per 100,000 personyears in the period from 2000 to 2009 ( $p<0.001$ ). The age and sexadjusted incidence of vertebral osteomyelitis increased from 0.5 case per 100,000 person-years in the period from 1969 to 1979 to 4.7 cases per 100,000 person-years in the period from 2000 to 2009.

\section{Survival}

During follow-up of the entire osteomyelitis cohort, we observed 386 deaths when 141.2 deaths were expected on the basis of age, sex, and calendar year-specific death rates in the Minnesota population. This difference corresponded to a standardized mortality ratio of 2.73 (95\% CI, 2.46 to 3.00), indicating that the risk of death is increased at least 2.5 -fold.

\section{Discussion}

T $\mathrm{n}$ this population-based study, we describe trends in the incidence of osteomyelitis over time and demonstrate that the epidemiology of osteomyelitis changed substantially over the four decades between 1969 and 2009. Although the published literature provides some information for selected subgroups and subtypes of osteomyelitis (e.g., pediatric patients, methicillinresistant $S$. aureus [MRSA]-related disease, and vertebral involvement $)^{29-31}$, this study is the first, as far as we know, to describe the population burden of osteomyelitis in the U.S. Our findings corroborate clinical observations and indicate that the incidence has increased over time, and is generally higher in males than in females. We further demonstrate that incidence rates remained relatively stable among children and young adults (less than fifty years old) but almost tripled among the elderly, mostly driven by a secular increase in diabetes-related cases. These intriguing findings underscore the importance of time trends and natural history studies in generating important etiological clues about the condition. Further research is needed to replicate these findings in other populations and to address potential preventive measures to curb the burden of osteomyelitis.

Age is an important factor in determining the etiology of osteomyelitis. The most common etiology in children is hematogenous infections. Previous studies from Norway ${ }^{32,33}$ and Lithuania $^{34}$ have noted an annual incidence of approximately ten to fourteen cases of hematogenous osteomyelitis per 100,000 children. On the other hand, a lower incidence of acute hematogenous osteomyelitis has been reported in Scotland in two separate studies of the Glasgow population between 1970 and 1997, with an annual incidence of 2.9 new cases per 100,000 population $^{35,36}$. These rates from Europe were much lower than the rates among Maori children, with a crude annual incidence as high as forty-three per 100,000 population ${ }^{37,38}$. In our study, about half $(48 \%)$ of pediatric osteomyelitis cases were hematogenous infections, $38 \%$ were mostly trauma-related contiguous infections, and 14\% were iatrogenic or diabetes-related infections. The overall incidence of osteomyelitis in children remained relatively stable over time (eight to ten cases per 100,000 person-years), as did the incidence by etiology. Although $S$. aureus infections comprised $65 \%$ of the pediatric hematogenous osteomyelitis cases in our cohort, we were unable to observe temporal trends with respect to MRSA infections since we did not collect information on methicillin sensitivity ${ }^{39}$. This is the subject of our ongoing analyses. 
Older adults are prone to osteomyelitis because they experience a higher frequency of disorders that lead to infection, such as orthopaedic surgeries and diabetes mellitus. Therefore, the higher incidence of osteomyelitis among older individuals in Olmsted County agrees with general clinical observations ${ }^{2,40}$. In particular, vertebral osteomyelitis is a rare condition with a reported incidence of approximately 2.2 to 2.4 cases per 100,000 person-years and a male-to-female ratio of $1.5^{21,31,41,42}$. We observed a significant increase $(\mathrm{p}<0.001)$ in the incidence of vertebral osteomyelitis over time (from 0.5 to 4.7 cases per 100,000 person-years), and the incidence was slightly higher in males than in females. S. aureus is the primary causative organism in the majority of vertebral cases, and some recent studies have described an increase in culture-negative cases as a result of early antibiotic administration ${ }^{43}$. We also observed a similar trend in our cohort, in which half of the vertebral osteomyelitis cases after 2000 were culture-negative.

The largest driver of the increase in osteomyelitis incidence over time in our study was diabetes. The incidence of diabetes-related osteomyelitis quadrupled from 2.3 to 10.5 cases per 100,000 person-years from the 1970s to the 1990s, but we observed a leveling off of the incidence at 7.6 cases per 100,000 person-years in the 2000s. Despite the large number of studies describing diabetic foot ulcers and lower-extremity amputations ${ }^{44-46}$, there are few studies specifically on the incidence and outcomes of osteomyelitis in this population. The incidence of foot osteomyelitis among patients with diabetes mellitus is estimated to be approximately $0.3 \%$ per year, with a lifetime risk of $4 \%^{47,48}$. In our study, $68 \%$ of patients with diabetes-related foot osteomyelitis had an amputation. This proportion is similar to those in other studies and remained relatively stable over the forty-one-year time period of our study, indicating that amputation is still relatively common once osteomyelitis develops. These findings are consistent with national data that indicate that forefoot or toe amputations have remained relatively stable over the previous decades ${ }^{49}$. Therefore, efforts should focus on effective prevention and treatment of diabetic foot disease since prognosis is poor once osteomyelitis develops.

The results of this study should be interpreted in light of some potential limitations. Although this is the first populationbased report of overall osteomyelitis incidence in the United States that we are aware of, the demographics of Olmsted County may not be representative of some ethnic and racial groups who may have a higher incidence of osteomyelitis ${ }^{25}$. A large proportion of osteomyelitis cases (43\%) were based on clinical diagnosis only without surgical sampling or needle aspiration biopsy. Otherwise, all cases were clinically and/or surgically managed as osteomye- litis. A notable strength of this study is the unique ability to review the original medical records to confirm the osteomyelitis diagnosis and collect detailed information on disease characteristics, medical management, and surgical interventions. This is rarely possible in other settings. S. aureus is well known as a leading cause of osteomyelitis and was present as the primary organism in about half of the cases in our cohort. The commonness of S. aureus is also important, given the present-day existence of MRSA strains. Unfortunately, we lack data on methicillin sensitivity and are unable to examine trends in the proportion of MRSA infections. We also did not collect details on tobacco use or the level of amputations. Despite these limitations, the present study documents the population burden of all types of clinically recognized osteomyelitis over four decades using a consistent case validation methodology. Published studies to date have tended to be mostly small retrospective case series focusing on a subset of patients or age groups. As part of our ongoing studies, we are monitoring additional aspects of osteomyelitis, including MRSA infections, the risk and predictors of amputations, and the presence and type of comorbidities.

In conclusion, this comprehensive review of all cases of osteomyelitis in a population-based setting over four decades indicates that osteomyelitis continues to be a substantial burden to patients, providers, and the health-care system. Despite notable changes in the epidemiology of the disease, the overall incidence of osteomyelitis increased over time and this was mostly driven by an increase in diabetes-related cases and vertebral osteomyelitis in recent years. Further research is warranted to replicate these findings in other populations and to address potential preventive measures to curb the increase in the burden of osteomyelitis.

Hilal Maradit Kremers, MD, MSc

Jeanine E. Ransom, BS

Christina M. Wood-Wentz, MS

L. Joseph Melton III, MD

Paul M. Huddleston III, MD

Departments of Health Sciences Research

(H.M.K., J.E.R., C.M.W.-W., and L.J.M.) and

Orthopedic Surgery (P.M.H.),

Mayo Clinic, 200 First Street S.W.,

Rochester, MN 55905.

E-mail address for H.M. Kremers: maradit@mayo.edu

Macaulay E. Nwojo, MD

Dignity Health St. Joseph's Hospital and Medical Center,

300 West Thomas Road,

Phoenix, AZ 85013

\section{References}

1. Berbari EF, Steckelberg JM, Osmon DR. Osteomyelitis. In: Mandell GL, Bennett JE, Dolin R, editors. Principles and practice of infectious diseases, 7 th ed. Philadelphia: Saunders Elsevier; 2009. p 1457-67.

2. Lew DP, Waldvogel FA. Osteomyelitis. Lancet. 2004 Jul 24-30;364(9431): 369-79.

3. Mader JT, Mohan D, Calhoun J. A practical guide to the diagnosis and management of bone and joint infections. Drugs. 1997 Aug;54(2):253-64.

4. Mader JT, Ortiz M, Calhoun JH. Update on the diagnosis and management of osteomyelitis. Clin Podiatr Med Surg. 1996 Oct;13(4):701-24.
5. Calhoun JH, Anger DM, Ledbetter BR, Cobos JA, Mader JT. The Ilizarov fixator and polymethylmethacrylate-antibiotic beads for the treatment of infected deformities. Clin Orthop Relat Res. 1993 Oct;295:13-22.

6. Cattaneo R, Catagni M, Johnson EE. The treatment of infected nonunions and segmental defects of the tibia by the methods of Ilizarov. Clin Orthop Relat Res. 1992 Jul;280:143-52.

7. Dendrinos GK, Kontos S, Lyritsis E. Use of the llizarov technique for treatment of non-union of the tibia associated with infection. J Bone Joint Surg Am. 1995 Jun;77 (6):835-46. 
The Journal of Bone \& Joint Surgery $\cdot$ Jbjs.org Volume 97-A - Number 10 - MAY 20, 2015
Trends in the EPidemiology of OSteomyelitis
8. Green SA. Osteomyelitis. The Ilizarov perspective. Orthop Clin North Am. 1991 Jul;22(3):515-21.

9. Gugenheim JJ Jr. The llizarov method. Orthopedic and soft tissue applications. Clin Plast Surg. 1998 Oct;25(4):567-78.

10. Grayson ML, Silvers J, Turnidge J. Home intravenous antibiotic therapy. A safe and effective alternative to inpatient care. Med J Aust. 1995 Mar 6;162(5):249-53.

11. Tice AD, Hoaglund PA, Shoultz DA. Outcomes of osteomyelitis among patients treated with outpatient parenteral antimicrobial therapy. Am J Med. 2003 Jun 15;114(9):723-8.

12. Osmon DR, Berbari EF. Outpatient intravenous antimicrobial therapy for the practicing orthopaedic surgeon. Clin Orthop Relat Res. 2002 Oct;403:80-6.

13. Pääkkönen $M$, Kallio MJT, Kallio PE, Peltola $H$. Shortened hospital stay for childhood bone and joint infections: analysis of 265 prospectively collected culturepositive cases in 1983-2005. Scand J Infect Dis. 2012 Sep;44(9):683-8. Epub 2012 May 8.

14. Pollak AN, Jones AL, Castillo RC, Bosse MJ, Mackenzie EJ; LEAP Study Group. The relationship between time to surgical debridement and incidence of infection after open high-energy lower extremity trauma. J Bone Joint Surg Am. 2010 Jan;92 (1):7-15.

15. Cierny G 3rd. Infected tibial nonunions (1981-1995). The evolution of change. Clin Orthop Relat Res. 1999 Mar;360:97-105.

16. Mader JT, Cripps MW, Calhoun JH. Adult posttraumatic osteomyelitis of the tibia. Clin Orthop Relat Res. 1999 Mar;360:14-21.

17. Lipsky BA, Berendt AR, Cornia PB, Pile JC, Peters EJG, Armstrong DG, Deery HG, Embil JM, Joseph WS, Karchmer AW, Pinzur MS, Senneville E; Infectious Diseases Society of America. Executive summary: 2012 Infectious Diseases Society of America clinical practice guideline for the diagnosis and treatment of diabetic foot infections. Clin Infect Dis. 2012 Jun;54(12):1679-84.

18. Centers for Disease Control and Prevention. Age-adjusted hospital discharge rates for non-traumatic lower extremity amputation per 1,000 diabetic population, by level of amputation, United States, 1993-2009. 2010. http://www.cdc.gov/ diabetes/statistics/lealevel/fig8.htm. Accessed $2015 \mathrm{Feb} 18$.

19. Gafur OA, Copley LAB, Hollmig ST, Browne RH, Thornton LA, Crawford SE. The impact of the current epidemiology of pediatric musculoskeletal infection on evaluation and treatment guidelines. J Pediatr Orthop. 2008 Oct-Nov;28(7):777-85.

20. Bates J, Mkandawire N, Harrison WJ. The incidence and consequences of early wound infection after internal fixation for trauma in HIV-positive patients. J Bone Joint Surg Br. 2012 Sep;94(9):1265-70.

21. Krogsgaard MR, Wagn $P$, Bengtsson J. Epidemiology of acute vertebral osteomyelitis in Denmark: 137 cases in Denmark 1978-1982, compared to cases reported to the National Patient Register 1991-1993. Acta Orthop Scand. 1998 Oct;69(5):513-7.

22. Gerber JS, Coffin SE, Smathers SA, Zaoutis TE. Trends in the incidence of methicillin-resistant Staphylococcus aureus infection in children's hospitals in the United States. Clin Infect Dis. 2009 Jul 1;49(1):65-71.

23. Vardakas KZ, Kontopidis I, Gkegkes ID, Rafailidis PI, Falagas ME. Incidence, characteristics, and outcomes of patients with bone and joint infections due to community-associated methicillin-resistant Staphylococcus aureus: a systematic review. Eur J Clin Microbiol Infect Dis. 2013 Jun;32(6):711-21. Epub 2013 Jan 20. 24. Rocca WA, Yawn BP, St Sauver JL, Grossardt BR, Melton LJ 3rd. History of the Rochester Epidemiology Project: half a century of medical records linkage in a US population. Mayo Clin Proc. 2012 Dec;87(12):1202-13. Epub 2012 Nov 28.

25. St Sauver JL, Grossardt BR, Leibson CL, Yawn BP, Melton LJ 3rd, Rocca WA. Generalizability of epidemiological findings and public health decisions: an illustration from the Rochester Epidemiology Project. Mayo Clin Proc. 2012 Feb;87(2): 151-60.

26. St Sauver JL, Grossardt BR, Yawn BP, Melton LJ 3rd, Pankratz JJ, Brue SM, Rocca WA. Data resource profile: the Rochester Epidemiology Project (REP) medical records-linkage system. Int J Epidemiol. 2012 Dec;41(6):1614-24. Epub 2012 Nov 18.

27. St Sauver JL, Grossardt BR, Yawn BP, Melton LJ 3rd, Rocca WA. Use of a medical records linkage system to enumerate a dynamic population over time: the Rochester Epidemiology Project. Am J Epidemiol. 2011 May 1;173(9):1059-68. Epub 2011 Mar 23.
28. Berbari EF, Hanssen AD, Duffy MC, Steckelberg JM, Ilstrup DM, Harmsen WS, Osmon DR. Risk factors for prosthetic joint infection: case-control study. Clin Infect Dis. 1998 Nov; 27(5):1247-54.

29. Shivarathre D, George H, Kaimal N, James L. Epidemiology of acute haematogenous osteomyelitis in children-a single unit's experience over three different time-periods. Acta Orthop Belg. 2009 Feb;75(1):81-6.

30. Lora-Tamayo J, Euba G, Narváez JA, Murillo O, Verdaguer R, Sobrino B, Narváez $J$, Nolla JM, Ariza J. Changing trends in the epidemiology of pyogenic vertebral osteomyelitis: the impact of cases with no microbiologic diagnosis. Semin Arthritis Rheum. 2011 Oct;41(2):247-55. Epub 2011 Jun 12.

31. Grammatico L, Baron S, Rusch E, Lepage B, Surer N, Desenclos JC, Besnier JM. Epidemiology of vertebral osteomyelitis (VO) in France: analysis of hospitaldischarge data 2002-2003. Epidemiol Infect. 2008 May;136(5):653-60. Epub 2007 Jun 14.

32. DahI LB, Høyland AL, Dramsdahl H, Kaaresen PI. Acute osteomyelitis in children: a population-based retrospective study 1965 to 1994. Scand J Infect Dis. 1998;30 (6):573-7.

33. Riise OR, Kirkhus E, Handeland KS, Flatø B, Reiseter T, Cvancarova M, Nakstad $\mathrm{B}$, Wathne KO. Childhood osteomyelitis-incidence and differentiation from other acute onset musculoskeletal features in a population-based study. BMC Pediatr. 2008;8:45. Epub 2008 Oct 20.

34. Malcius D, Trumpulyte G, Barauskas V, Kilda A. Two decades of acute hematogenous osteomyelitis in children: are there any changes? Pediatr Surg Int. 2005 May;21(5):356-9. Epub 2005 Apr 15.

35. Craigen MAC, Watters J, Hackett JS. The changing epidemiology of osteomyelitis in children. J Bone Joint Surg Br. 1992 Jul;74(4):541-5.

36. Blyth MJG, Kincaid R, Craigen MAC, Bennet GC. The changing epidemiology of acute and subacute haematogenous osteomyelitis in children. J Bone Joint Surg Br. 2001 Jan;83(1):99-102.

37. Gillespie WJ. The epidemiology of acute haematogenous osteomyelitis of childhood. Int J Epidemiol. 1985 Dec;14(4):600-6.

38. Rossaak M, Pitto RP. Osteomyelitis in Polynesian children. Int Orthop. 2005 Feb;29(1):55-8. Epub 2004 Oct 14.

39. Saavedra-Lozano J, Mejías A, Ahmad N, Peromingo E, Ardura MI, Guillen S, Syed A, Cavuoti $\mathrm{D}$, Ramilo $\mathrm{O}$. Changing trends in acute osteomyelitis in children: impact of methicillin-resistant Staphylococcus aureus infections. J Pediatr Orthop. 2008 JulAug;28(5):569-75.

40. Cunha BA. Osteomyelitis in elderly patients. Clin Infect Dis. 2002 Aug 1;35 (3):287-93. Epub 2002 Jul 11.

41. Beronius M, Bergman B, Andersson R. Vertebral osteomyelitis in Göteborg, Sweden: a retrospective study of patients during 1990-95. Scand J Infect Dis. 2001;33(7):527-32.

42. Hutchinson $C$, Hanger $C$, Wilkinson $T$, Sainsbury R, Pithie A. Spontaneous spinal infections in older people. Intern Med J. 2009 Dec;39(12):845-8.

43. Kehrer M, Pedersen C, Jensen TG, Lassen AT. Increasing incidence of pyogenic spondylodiscitis: a 14-year population-based study. J Infect. 2014 Apr;68(4):31320. Epub 2013 Dec 1.

44. Moxey PW, Gogalniceanu P, Hinchliffe RJ, Loftus IM, Jones KJ, Thompson MM, Holt PJ. Lower extremity amputations-a review of global variability in incidence. Diabet Med. 2011 Oct;28(10):1144-53.

45. Unwin N, Mackintosh J, Grp GLS. Epidemiology of lower extremity amputations and proportion associated with diabetes in centres in Europe, North America, and East Asia. Diabetologia. 1999 Aug;42:A305-A.

46. Gregg EW, Li Y, Wang J, Burrows NR, Ali MK, Rolka D, Williams DE, Geiss L. Changes in diabetes-related complications in the United States, 1990-2010. N Engl J Med. 2014 Apr 17;370(16):1514-23.

47. Peters EJG, Lipsky BA. Diagnosis and management of infection in the diabetic foot. Med Clin North Am. 2013 Sep;97(5):911-46. Epub 2013 Jun 5.

48. Ramsey SD, Newton K, Blough D, McCulloch DK, Sandhu N, Reiber GE, Wagner $\mathrm{EH}$. Incidence, outcomes, and cost of foot ulcers in patients with diabetes. Diabetes Care. 1999 Mar;22(3):382-7.

49. Goodney PP, Tarulli M, Faerber AE, Schanzer A, Zwolak RM. Fifteen-year trends in lower limb amputation, revascularization, and preventive measures among Medicare patients. JAMA Surg. 2015 Jan 1;150(1):84-6. 